\title{
The dietary prevention of coronary heart disease: dietary cholesterol and fat
}

\author{
William E. CONNOR \\ M.D. \\ Department of Medicine, University of Oregon, Health Sciences Center, Portland, Oregon 97201
}

\begin{abstract}
Summary
Epidemiological, laboratory and experimental studies make it clear that dietary cholesterol (DC) and saturated fat, independently and together, are hypercholesterolaemic and atherogenic. Some work suggests that DC, usually given as egg yolk, is the more important, but often they are consumed together. There is a threshold, usually between 100 and 200 $\mathrm{mg} / \mathrm{day}$, below which small increments do not affect plasma cholesterol (PC) and another, usually between 500 and $600 \mathrm{mg} /$ day, above which there is little additional change. However, there is considerable individual variation. Recent work suggests that regression of atherosclerosis can occur in the human as in the non-human primate. An alternative, phased, preventive diet has been designed which is nutrionally adequate, ecologically sound, and economical. It also has an historical basis.
\end{abstract}

\section{Introduction}

The notion that diet is related to coronary heart disease (CHD) and atherosclerosis has a long history going back to the Dutchman de Langen who worked on the island of Java from 1908 (1916). He was a pathologist and made the first original observation that the Dutch settlers were dying of CHD, but not the Javanese whose arteries were not occluded. He correctly deduced that this had to do with their different diets, the native diet being mainly rice, vegetables and fruit and that of the Dutch being the conventional diet of the Western world at that time. He must be given credit for being the first to make that observation. Also, he made the first metabolic ward experiments by feeding the Dutch diet to the Javanese and noting that plasma cholesterol was increased (de Langen, 1922).

There are 4 sources of evidence about the relationship of diet to plasma cholesterol (PC) concentrations and CHD. The first refers to epidemiology; the second refers to experimental atherosclerosis in many species including sub-human primates, which takes us a littie closer to man; the third refers to human metabolic ward experiments which allow us decisively to isolate the dietary factors which influence PC. Finally, some clinical trials have been performed, although not all have been positive.

Biochemically an atherosclerotic lesion is composed of 3 substances; lipid, fibrous tissue protein or collagen, and scar tissue. The scar tissue arises as a reaction to the presence of lipid. The lipid is cholesterol and cholesteryl esters which increase many times and are the chief components of the biochemical lesion; therefore we have to ask ourselves the question where this lipid is coming from. Is it synthesized in the wall of the artery or does it come from the blood? If it does come from the blood, can we control the blood lipid concentrations? Furthermore, is it fixed in the tissue or can it move in and out?

\section{Epidemiology}

First we must consider the epidemiological findings. In Japan and in the countries of the Mediterranean basin, the incidence of CHD is low (Connor and Connor, 1972). In Finland, the United States of America, the United Kingdom, New Zealand, Australia and Canada it is very high. PC in these different populations likewise correlates with the dietary cholesterol intake and with the death rate from CHD. In the U.S.A., PC levels were 240 $250 \mathrm{mg} / \mathrm{dl}$ in men of 55-59 years, and in Japan these were much lower at $160-180 \mathrm{mg} / \mathrm{dl}$. The incidence of coronary risk factors (such as blood lipids and lipoproteins, blood pressure, obesity and the diet) have been studied in another population, the Tarahumara Indians in Chihuahua Province of Mexico, who are physically very active (Connor et al., 1978). Their diet was very interesting because it was complete as regards the amino acid content, yet they ate very little animal protein. It was quite an adequate diet, but very low in fat and cholesterol, particularly saturated fat. Dietary cholesterol intake was only $71 \mathrm{mg} /$ day compared with $500-800 \mathrm{mg} /$ day in the U.S.A. Total fat was of the order of $12 \%$ of the calories compared with $\mathbf{4 0} \%$ in the U.S.A. Plasma cholesterol levels were low $(120-130 \mathrm{mg} / \mathrm{dl})$ and did not rise very much with age. 


\section{Experimental atherosclerosis}

Experiments with rhesus monkeys: Control groups were given monkey feed and the experimental group was given a diet rich in egg yolk which contains adequate essential fatty acids (Armstrong, Warner and Connor, 1970). Thus there was no deficiency of essential fatty acids in this experiment. Monkeys consuming $40 \%$ of the total fat calories from egg yolk developed a rise in PC which is an invariable result of feeding animals foods containing cholesterol and fat. A wide variety of species has had this particular response. The experiment continued for 17 months, after which some animals were studied at post-mortem and the others were given a dietary programme to investigate the possibility of regression. The lesions which developed initially very much resembled the human lesion, with accumulations of fat and cholesterol, fibrosis and resultant narrowing of the lumen. In the regression groups with initially comparable lesions, one was given a low fat-low cholesterol diet, and the other a low cholesterol diet which was high in polyunsaturated corn oil. Both groups were observed for a period of 3 years and remained healthy. Plasma cholesterol was reduced and xanthomatous lesions regressed with widening of the arterial lumen. The reduction was on average $61 \%$ occlusion to only $20 \%$ occlusion, and chemically the lesions lost much cholesterol and cholesteryl esters.

It is clear from literally hundreds of experiments that dietary cholesterol and saturated fat are atherogenic. Regression of lesions has been shown after removal of dietary cholesterol and fat. However, the group receiving corn oil had exactly the same amount of regression as the low fat group so that one cannot say that the addition of polyunsaturated fat in the monkey has any particular advantage over the amount that the animal needs for its essential fatty acid requirement. The crucial factor seemed to be removal of the dietary cholesterol.

\section{The human situation}

If $\mathbf{P C}$ is high, the influx of cholesterol into the arterial wall is greater than the efflux and a deposit ultimately occurs with growth of the atheromatous plaque. It is hypothesized that regression occurs in man as has been shown in animals. Obviously, the way to prevent atherosclerosis in man is not to consume dietary cholesterol and saturated fat, and not to have high PC levels. The possibilities for treatment and reversibility are evident.

In man the only sterol of importance is cholesterol. The kind and amount of fat is of considerable importance in determining PC levels, but in this author's experience the effect of saturated fat is more decisive than that of polyunsaturated fat in determining PC. Also, the number of calories in the diet is of critical importance because this seems to set the 'thermostat' of the body in regulating cholesterol metabolism at an upper level. In other words, overweight people with adiposity will generally have PC levels higher than would otherwise be the case. Carbohydrates are of lesser importance, but there are some trends indicating that complex carbohydrates, such as starch, may have a mild cholesterol lowering effect, particularly when coupled with fibre. If proteins, minerals and vitamins are adequately present in the diet, they do not have an influence on PC, nor does salt have any influence on PC, but there is a very strong relationship of salt to hypertension.

\section{Clinical trials}

In one human experiment, $P C$ rose from $160 \mathrm{mg}$ $240 \mathrm{mg} / \mathrm{dl}$ when an individual consumed a high cholesterol diet similar to that used in the experimental animal work, but composed of natural human food. PC rose within 3-4 weeks and the peak values were about $60-80 \mathrm{mg} / \mathrm{dl}$ higher, which is a similar difference to that between the Western world and Japan. In another study there was considerable individual diversity but, under metabolic ward conditions, dietary cholesterol was firs removed and then one $\mathbf{g}$ was added to the diet wit everything else kept constant. Removal of choles terol from the food reduced plasma cholesterol by $30-50 \mathrm{mg} / \mathrm{dl}$ and, when cholesterol was added to the diet, the mean change was an increase of $36 \mathrm{mg}$ in the blood, but as much as $67 \mathrm{mg}$ in some individuals with severe hypercholesterolaemia (Connor and Connor, 1972; Glueck and Connor, 1978).

It is thus concluded that dietary cholesterol is of very great importance in influencing plasma cholesterol, and in these experiments the source was egg yolk. The lipoprotein change was in general confined to the beta or low density lipoprotein, as in rhesus monkeys fed egg yolk, and this is the lipoprotein found in atheromatous plaques. It is the conveyor of most of the cholesterol in the plasma.

There seems to be a threshold amount of dietary cholesterol below which small increments do not affect PC. The threshold is probably between 100 and $200 \mathrm{mg} /$ day. Also, if one consumes excessive increments of dietary cholesterol, one reaches a ceiling above which there is no additional change in plasma cholesterol. There may be changes in the body with the storage of cholesterol being more marked, but it is not evident in the blood. If dietary cholesterol intake is increased from 500 to 1000 $\mathrm{mg} /$ day, over an observation period of 4 weeks, no change occurs. In other words, the ceiling has been reached. This probably accounts for some of the confusion in the literature. The ceiling may be 
different for different individuals, but the main issue is of the range between threshold and ceiling.

What about the effects of weight loss? Plasma triglyceride and cholesterol concentrations invariably fall in subjects who are hypercholesterolaemic.

The recent report by Blanksenhorn is also of considerable interest (Blanksenhorn et al., 1978). He lowered PC, treated BP effectively and measured angiographically the amount of atherosclerosis in the femoral arteries. There were 2 kinds of results. There was progression of the disease in those patients who had no lowering of PC, but in the other group there was some reversibility of atherosclerosis. This is a positive clinical investigation and in future this method is likely to be used because conventional clinical trials are too expensive and too difficult. Serial angiography is simpler and serial observations can be made in the same individual.

In the U.S.A. there has been a decline in mortality from CHD of $12-27 \%$ at all ages in men and women, white and black. During the last few years there has been a change in diet with a reduction in saturated fat intake, of butter and of eggs, with some increase in the use of vegetable oils and margarines. Plasma cholesterol concentrations have declined. In one group of 50000 individuals reported by the National Health Survey, the average decline in PC was $5-6 \mathrm{mg} / \mathrm{dl}$ in all ages. The author and his colleagues have also sampled a population of school children in Muscatine in Iowa (unpublished data) and, instead of a mean value of $180 \mathrm{mg} / \mathrm{dl}$ which they reported some 5 years ago, the values are now about $170 \mathrm{mg} / \mathrm{dl}$, and other groups have found lower values.

An alternative or disease prevention diet is recommended, designed for America, but which could be used in Britain as well. It is nutritionally adequate and ecologically sound. It is one which people can afford, not only in rich, but also in poor countries. It has some historical basis, as shown in most of the world's great civilizations. The diet of ancient Egypt, except for the Pharaohs, was rich mainly in cereals and vegetables. In China it was rice and vegetables with only small quantities of animal products. The author thinks that patients and populations will change their diet very slowly. It may take one to 10 years in a series of phases. He has suggested 3 phases, but it might take many more.

In Phase I, the first recommendation is a change to margarine from butter. In the U.S.A. this has largely been accomplished and is easy to do. The second is a change from animal shortenings and lard to vegetable oils. This has likewise been accomplished fairly easily. Then, skimmed milk should be produced from whole milk, which is a little more of a problem, but most people are willing to do it because the calorie value of skimmed milk is about half that of whole milk and they are interested in attending to their excess weight as well. The nutrients which are of particular importance in milk, for example calcium and protein, are of course still present. Egg whites and egg substitutes are often used for whole eggs. Most recipes call for whole eggs, but it is possible to use egg whites, say 3 whites for every 2 yolks. Consumption of offal should also be reduced since this has the highest cholesterol of all meats. Light salt which is a mixture of sodium and potassium chloride is also recommended, a slight change which most people may be willing to accept.

In Phase II, one needs to use more whole grains and legumes. This is a little harder to accomplish. This phase also includes increased consumption of fruit and vegetables. One can also concentrate on low fat meats, fish and poultry, skimmed milk cheeses and less salt. In Phase III, meals should consist largely of whole grains with beans and other legumes, fruit, vegetables and skimmed milk, but small amounts of poultry, fish, meat or low fat cheese are permitted. In other words, meat is used as a condiment. In recognizing that even the Tarahumara Indians had feast days, it is suggested that there should be feast days, and they be enjoyed without any feeling of guilt. People can eat what they want on these occasions, unlike the current situation where every day is a feast day.

When this is done sequentially the amount of dietary cholesterol will fall from about 500 to $100 \mathrm{mg} /$ day. It is necessary to take a long-term view, involving reduction in dietary cholesterol from 500 to $350 \mathrm{mg}$ in Phase I and down to $200 \mathrm{mg}$ in Phase II. At the same time, the amount of total fat should be decreased from $40-20 \%$ (Phase III) of the energy. This decrease will be largely in the form of saturated fat which, it is suggested, should not exceed $6 \%$ of total calories. Polyunsaturated fat need not be increased, yet already represents $6-9 \%$ of total calories. Carbohydrate must increase to about 65$70 \%$ of total calories, mainly as starch, with a sequential increase as fat consumption declines. The Tarahumara Indians eat about $75-80 \%$ of their diet as carbohydrate.

This pattern divides food into 6 groups, including whole grains, legumes, nuts and seeds, vegetables and fruit, vegetable oils and margarines and low fat animal products. It is not, however, a vegetarian diet. Vitamin $\mathbf{B}_{12}$ is essential for human nutrition and would be adequately supplied by fish, skimmed milk, poultry and small amounts of other meats.

It is suggested that for children and young adults the goal should be a PC below $180 \mathrm{mg} / \mathrm{dl}$; for slightly older adults about $200 \mathrm{mg}$, and at the age of 45 years and over the goal should be $220 \mathrm{mg} / \mathrm{dl}$ 
or below. Obviously, the ideal goal would be a level of PC similar to that of the Japanese-140-160 $\mathrm{mg} / \mathrm{dl}$.

[In discussion, the author was asked whether serum cholesterol was more sensitive to dietary cholesterol intake or to that of saturated fat, and did these two interact? He replied that they certainly interacted and were synergistic. It happens that most of the foods which contain cholesterol also contain saturated fat, and it was difficult to establish which were more important. On the basis of his own work, he thought dietary cholesterol was the more important, but saturated fat also played a role. Both should be reduced.

The author said in reply to a further question that plant steroids were only important in a few genetically susceptible individuals. As regards peanuts, for example, he though that they were an excellent source of nutrition and did not contain cholesterol. Their high fat content would limit their use to only moderate quantities. A problem had arisen because of atherosclerosis being produced experimentally by feeding animals with peanuts. However, the lesions were different in some respects from human lesions and the quantities used much greater than those normally consumed by man.]

\section{References}

Armstrong, M.L., Warner, E.D. \& Connor, W.E. (1970) Regression of coronary atheromatosis in rhesus monkeys. Circulation Research, 27, 59.

Blanksenhorn, D.B., Brooks, S.H., Selzer, R.H. \& BRANDT, R. (1978) The rate of atherosclerosis change during treatment of hyperlipoproteinemia. Circulation, 57, 355 .

Clarke, W.R., Schrott, H.G., Leaverton, P.E., Connor, W.E. \& LAUER, R.M. (1978) Tracking of blood lipids and blood pressures in school age children: The Muscatine Study, 58, 626.

Connor, W.E., Cerqueira, M.T., Connor, R.B., Malinow, M.R. \& CASDORPH, H.R. (1978) The plasma lipids, lipoproteins and diet of the Tarahumara Indians of Mexico. American Journal of Clinical Nutrition, 31, 1131.

Connor, W.E. \& Connor, S.L. (1972) The key role of nutritional factors in the prevention of coronary heart disease. Preventive Medicine, 1, 49.

ConNOR, W.E. \& ConNOR, S.L. (1977) Dietary treatment of hyperlipidemia. In: Hyperlipidemia: Diagnosis and Therapy (Ed by Rifkind, Basil M. \& Levy, Robert, I.) pp. 281-326. Grune \& Stratton, Inc. New York.

Glueck, C.J. \& ConNOR, W.E. (1978) Diet-coronary heart disease relationships reconnoitred. American Journal of Clinical Nutrition, 81, 727.

De LANGen, C.D. (1916) Cholesterol metabolism and racial pathology. Geneeskundig tijdschrift voor NederlandschIndië, 56, 1.

DE LANGEN, C.D. (1922) Cholesterol content of blood in India Geneeskundig tijdschrift voor Nederlandsch-Indië, 62, 5 . 